\title{
La creación como investigación: aportes para la reflexión desde la experiencia en la Universidad Central
}

Fecha de recepción: 12 de julio de 2018

Fecha de aprobación: 24 de noviembre de 2018

\section{Resumen}

El objeto de este artículo es la reflexión en torno a la noción de investigación en los programas de formación en artes y las posibilidades de los modos de producción de conocimiento fundamentados en la creación, de manera particular, en creación literaria. Primero, se presentan algunos aspectos importantes de la relación investigación-creación en el campo de las artes; segundo, reflexionamos sobre la delimitación de la creación como producción de conocimiento nuevo; finalmente, presentamos la experiencia de los programas de Creación Literaria de la Universidad Central.

Palabras clave: investigación, creación, producción de conocimiento, creación literaria.

Citar: Gutiérrez Mavesoy, A. \& Rodríguez Peña, A. (enero-junio de 2019). La creación como investigación: aportes para la reflexión desde la experiencia en la Universidad Central. La Palabra, (34), 55-69. (i) https://doi.org/10.19053/01218530. n34.2019.9528

\section{Aleyda Gutiérrez Mavesoy \\ Doctora en Literatura de la Univer- sidad de Sao Pablo. Directora del Departamento de Creación Litera- ria, Universidad Central. \\ agutierrezm@ucentral.edu.co}

\section{Adriana Rodríguez Peña}

Magíster en Literatura de la Universidad Javeriana. Coordinadora Académica de los Posgrados en Creación Literaria, Universidad Central.

arodriguezp@ucentral.edu.co

* Artículo de reflexión 


\title{
the Reflection from the Experience of Universidad Central
}

\begin{abstract}
The object of this article is the reflection about the notion of research on artistic formation programs and the possibilities of characterizing modes of knowledge production based on creation, specifically literary creation. First of all, we present some important aspects about the relation between research and creation in the field of the Arts. After this, we reflect creation as a field of production of new knowledge, and finally, we present the experience of the Literary Creation programs at Universidad Central.
\end{abstract}

Key Words: research, creation, knowledge production, literary creation

\section{¿Vigencia de un debate?: antecedentes de la cuestión}

La formación en creación literaria en el país empezó con los talleres de creación ${ }^{1}$ entre los años sesenta y ochenta. Pasarían más de veinticinco años para que surgieran los primeros programas universitarios dedicados a la formación en escritura creativa y en creación literaria. ¿Qué es lo que ha hecho tan lenta la inclusión de la creación literaria en el campo de la formación en artes? En el campo cultural, y no solo académico, desde el siglo XIX se ha pensado la formación en artes plásticas, la música, la danza y otras artes afines, pero, para el caso de la literatura, solo bien entrado el siglo XX y a través de la educación no formal que representan los talleres, es que se empezó a pensar en ello. ¿Por qué esta resistencia? Es posible que esté asociada a la imagen del escritor como demiurgo, el hacedor de mundos que desconoce el proceso que le llevó a la construcción de dichos mundos, una idea que el romanticismo ha sabido instalar, no solo en el imaginario popular, sino también en el artístico.

Sin detenernos en las particularidades de los programas de pregrado y posgrado existentes en la actualidad $^{2}$, podemos resumirlos en el hecho de que buscan ahondar en el conocimiento de las potencialidades que la formación ofrece en torno al lenguaje y en el desarrollo de las competencias estéticas para la creación de diferentes tipos de textos, en distintos géneros; además de la producción de contenidos, la discusión sobre la labor del escritor, los procesos que atañen a la creación. En

1 Eutiquio Leal fundó en 1962, con la ayuda de Roberto Burgos Ojeda, el primer taller de Escritura Creativa en la Universidad de Cartagena. Isaías Peña, creó el Taller de Escritores de la Universidad Central- TEUC,1981.

2 Los programas universitarios en Escritura Creativa y Creación Literaria creados en el país, son: Universidad Nacional de Colombia, Maestría en Escritura Creativa (2007); Universidad Central, Especialización en Creación Narrativa (2008), Pregrado en Creación Literaria (2010) y Maestría en Creación Literaria (2013); 
síntesis, se trata de pensar la formación de profesionales de la escritura -sea esta de ficción o de no ficción-. Es posible que esta idea de "profesionalización" o de "especialización" sea la que tanta resistencia presenta en torno a la formación en creación literaria.

Con la llegada de estos programas a la academia -además de aquellos de formación en artes plásticas, música, teatro, artes vivas y diseño, ya existentes-, el debate en las universidades sobre la investigación en las artes, ha generado múltiples cuestionamientos:

¿qué clase de conocimiento construye la investigación artística?, ¿qué es la investigación artística?, ¿no es el arte en sí mismo el producto de una investigación?, ¿no es la creación en sí misma una forma de investigar?, ¿no es el acto de escritura profundamente creador? La reflexión que aquí se propone parte de la presentación de algunos aspectos centrales de la relación investigación-creación en el campo de las artes; posteriormente, reflexionamos sobre la delimitación de la creación como producción de conocimiento nuevo; y finalmente, presentamos la experiencia de los programas de Creación Literaria de la Universidad Central.

Para Henk Borgdorff (2010), las formas particulares de producción de conocimiento en las artes, se distinguen de otras formas de investigación, porque contienen elementos tanto de filosofía, epistemología y metodología como de políticas y estrategias docentes. Lo esencial en la reflexión sobre esta forma de investigación, indica Borgdorff, es pensar "si existe un fenómeno como la investigación en las artes, según el cual la producción artística es en sí misma una parte fundamental del proceso de investigación, y la obra de arte es, en parte, el resultado de la investigación" (p. 1). Asimismo, es importante identificar “¿En qué se diferencia la investigación artística de la llamada investigación académica o científica?” (p. $4)$.

Las consideraciones de Borgdorff son sustanciales en la comprensión de la investigación artística, y tal vez puedan ayudar a configurar los desafíos centrales del debate, ya que, al considerar el proceso de investigación como parte constitutiva de la investigación artística y producción de la obra, se modifican y amplían los protocolos de la investigación de las ciencias sociales y humanas.

Otro aspecto sobre el que es necesario detenerse, tiene que ver con la nominalización de las formas de investigación en las artes: investigación creación o investigación artística. La perspectiva de los discursos homologadores en el campo de la educación artística, según Rubén López Cano (2014), ha equiparado la noción de educación artística con la noción de investigación a los procesos de creación, que incluyen la búsqueda de información y reflexión sobre la creación en el campo sonoro, visual, corporal, ya que para ellos "la experiencia artística es en sí misma una experiencia cognoscitiva" (López, 2015, p. 1). Se ha denominado investigación artística a una actividad específica "cuyo objetivo no se agota en el conocimiento generado por la obra en sí misma, sino que implica la reflexión crítica sobre diferentes elementos de la práctica artística, como el proceso creativo, los hábitos y rutinas de estudio, las influencias teóricas y prácticas, etc." (López, 2014, p. 39). Podemos entonces concluir que la investigación artística refiere al proceso de creación de la obra, y a la reflexión crítica sobre ella. 
También, está la perspectiva de los discursos hegemónicos desarrollados por las instituciones. Este enfoque establece diferencias entre investigación artística, creación artística e investigación científica o académica, para señalar que comparten prácticas de investigación "que articulan aspectos, momentos y tareas, se destacan por su actividad promotora de la investigación artística y que generan gran cantidad de discursos, libros, artículos, etc.” (López, 2015, p. 2).

Lo anterior nos permite profundizar en la comprensión de las formas de construcción de conocimiento de la investigación artística. La investigación científica no se puede homologar a la investigación artística, en tanto que la segunda es una actividad que no solo da cuenta de la enciclopedia, de las influencias teórico prácticas, de la conciencia de creación en su condición de azar y misterio, también de la reflexión crítica sobre la práctica artística. Se trata de que "no consintamos por más tiempo el dictado presuntuoso e impersonal del científico: en toda teoría esta su observador [...]”" (Chantal Maillard, 2017,

p. 379); se trata de "hacer virtud de la apariencia: aparezca el autor en lo escrito, el científico en su teoría y se relativice así el dictado, para no mentir tanto" (p. 37).

Ahora bien, antes de continuar, es necesario precisar qué se entiende por creación literaria. La etimología del término "creación literaria" obedece a una distinción conceptual básica: mientras en el mundo anglosajón suele ser corriente la aplicación de la expresión "creative writing" (escritura creativa) para referirse a la escritura de obras literarias, desde la corriente europea, se prefiere la denominación "creación literaria". En el mundo hispano, predomina el uso europeo, debido, por un lado, a la tradición latina; y por otro, a que el término "escritura creativa" puede conducir a ambivalencias.

En nuestro ámbito académico, el término hace referencia, en primer lugar, al trabajo pedagógico de los maestros encaminado a que los estudiantes adquieran competencias en el dominio de la lengua. En segundo lugar, se refiere a las formas en que se produce el discurso con predominio de la función estética, propio de la publicidad, el periodismo u otras disciplinas afines. En tercer lugar, se refiere al empleo que de la discursividad literaria hacen las ciencias para explicar fenómenos sociales o naturales. Finalmente, desde la psicología, se ha distinguido entre el conocimiento producto del pensamiento lógico matemático y el conocimiento producto del pensamiento narrativo.

Por todo ello, utilizar el término "escritura creativa" genera un problema conceptual evidente: la polivalencia conceptual del vocablo. Por esta razón, preferimos en nuestro medio el uso común del mundo académico: la expresión "creación literaria" para delimitar, aclarar y especificar el tipo de discurso literario con fines primordialmente estéticos.

Al aproximarnos a la complejidad de la comprensión de las formas de investigación en las artes, es urgente pensar el acto de creación y los procesos de la experiencia creadora, los métodos y las prácticas. Si llevamos estos elementos al campo específico de la creación literaria-como un campo de estudio reciente en el ámbito universitario, que se ha venido consolidando en el país-, es oportuno examinar: ¿cómo se entiende la investigación en creación literaria?, ¿qué áreas del trabajo en creación literaria se podrían denominar investigación?, ¿cuáles son las condiciones de legitimidad del conocimiento que produce la creación? 


\section{La creación literaria como investigación}

¿Qué significa crear en el campo literario? La respuesta obvia es hacer surgir lo nuevo a partir de lo ya existente. Si seguimos la idea de la literatura como biblioteca universal (un libro remite a otro libro, escribiría Mallarme), podríamos extender la imagen y considerar que la obra literaria se inscribe en la literatura como creación: sobre las bases de la biblioteca surge el texto que le falta a la biblioteca, pero que no la completa, en la medida en que en ella siempre queda vigente el espacio vacío para la nueva obra. Esta conciencia de finitud y de parcialidad es lo que lleva al acto de crear por caminos diferentes a los del discurso científico, no pretende llegar a la verdad, sino que al explorar apunta a su potencia de ser verdad. A esta potencia, suele denominarse verosimilitud y el imaginario popular asimila a la mentira. Ese es el problema fundamental de la creación literaria: equiparar ficción a una cara opuesta o negativa. La verdad es siempre verdad, y la ficción es mentira o es falsedad. Cualquiera de las dos opciones la saca de plano del campo de conocimiento.

Se establece, de este modo, la dicotomía discurso científico=verdad; discurso literario=verosimilitud. Pensemos esta última, idea "similar a la verdad" que evoca a la mimesis aristotélica: la búsqueda de la forma que permite alcanzar la imitación de la perfección de la naturaleza. Para los griegos en tiempo de Aristóteles, la naturaleza es perfecta, el fin esencial del arte sería tratar de alcanzar dicha perfección. Entonces, desde esta perspectiva, verdad y verosimilitud son caminos que conducen por vías distintas al conocimiento. La una intenta explicar desde las constantes, la otra desde las posibilidades. Bastante se ha dicho ya sobre el discurso científico como expresión de lo que es y el literario de lo que puede ser.

Esa indefinición de la creación literaria ha sido al mismo tiempo su poder y su condena. Su poder porque va más allá de la verdad del discurso científico para abrir el abanico de las pequeñas verdades de los discursos sociales en el texto artístico. Esta puesta en diálogo de los discursos de primer grado transforma a la creación en un lenguaje de segundo grado. Su condena porque en esa indefinición, como potencia, multiplica la posibilidad de las significaciones de lo real, al escapar de las constantes y provocar la connotación se le excluye del campo del conocimiento académico (que por definición pugna por la denotación) para instalarlo en el campo de la sensibilidad (espacio de las emociones, lugar de las indeterminaciones) al que suele asociarse con el saber producto de la experiencia en la vida práctica.

La intuición ha sido abanderada de la creación. Unida al concepto de creación igual ficción, igual verosimilitud; se piensa al acto creador como un proceso guiado por la intuición. Por diversas razones que no vienen al caso, algunos artistas insisten en esa indefinición de su quehacer, ese "no sé qué" que hace surgir la obra. La intuición, en tanto que capacidad más allá de la razón, se sale de las explicaciones lógicas causales. La intuición, como ejercicio de la imaginación, es uno de los motores de la creación literaria. Todo ello es cierto, pero no es el único. El lenguaje verbal, por su misma condición, limita y, al mismo tiempo, potencia la creación al poner en juego a la intuición de la mano de la racionalización para mover el proceso creador.

Justamente porque el acto de escribir es ficcional, en tanto que activa el lenguaje verbal, no es racional. El problema es que, por esa misma condición, tampoco es irracional. Llegados a este punto, podríamos considerar que la manera como pensamos a la intuición es la dificultad mayor para entender lo que 
sucede con los procesos de creación. En ella, se juega toda la historia personal del sujeto que escribe, su percepción y valoración del mundo, pero también su enciclopedia personal de las artes y del campo literario. La combinación entre cada uno de estos componentes en el texto literario es lo que denominamos proceso de creación. Este proceso no es intuitivo totalmente, ni tampoco cien por ciento racional, podemos aceptar que a medio camino de uno y otro (ni irracional ni racional) se instaura lo no-racional como vía en la que se encuentran la intuición y la razón en el proceso de creación.

La reflexión que se propone tiene en cuenta el ejercicio de formalización y puesta en marcha de los programas dedicados a la formación de profesionales de pregrado y posgrado en creación literaria, desarrollados por el Departamento de Creación Literaria de la Universidad Central en los últimos diez años.

Las ideas sobre la creación literaria, los principios epistemológicos, teóricos, metodológicos, y las preguntas en torno a la investigación que produce la creación literaria, muestran una ampliación de la visión objetivista del método científico y señalan algunas de las definiciones académicas fundamentales que han permitido la configuración de estos programas.

Los programas en Creación Literaria de la Universidad Central pretenden "distanciarse del marco de la cultura científica que trata la obra literaria desde una visión pretendidamente objetivista, para centrarse en el acto de la creación desde una visión estética"’. $[\ldots]$

En la ciencia de la literatura o estudios literarios convergen la teoría de la literatura, la crítica, la historiografía, la historia literaria y la literatura comparada. Los distintos paradigmas del siglo XX han abordado el estudio de la obra literaria desde un enfoque científico al tomar prestado de otras ciencias los procesos metodológicos y perspectivas teóricas. La investigación literaria ha centrado su quehacer en "la teoría, la crítica y la historia, y ha abandonado la labor literaria del creador por „carecer de ese modelo sistemático“ de búsqueda al que se ha denominado „método científico "e y porque su orientación no se enfoca hacia la explicación de los hechos, sino hacia su resignificación en la escritura”. (Universidad Central, 2017, pp. 15, 23).

Sin embargo, esto no significa que, para construir un programa de Creación Literaria, le damos la espalda a los Estudios Literarios. Uno de los propósitos centrales es circunscribir la creación literaria a los estudios literarios. Las perspectivas teóricas en las que se basa nuestra propuesta, entienden la creación literaria

desde la teoría literaria (estética de la recepción, la intertextualidad, el dialogismo y la palabra, la distinción entre lisibli y scriptible), los estudios culturales (la desintegración, la deconstrucción y diseminación), la psicología (el inconsciente como parte de las redes externas del sujeto hablante), la historia (como la versión de la ficción narrativa, la metáfora del juego) la filosofía (la fenomenología, el acontecimiento, la hermenéutica, la intencionalidad, etc.) o cualquiera de las disciplinas que dialogan con la obra de creación literaria. (Universidad Central, 2017, p. 25).

Esta mirada interdisciplinar favorece la configuración y consolidación del campo de la creación literaria como objeto de estudio, así como las diversas posibilidades de investigación del sujeto creador. Más que clasificar o valorar las obras terminadas, nos interesa entender los movimientos creadores en tensión

3 Documento de campo de estudio de los programas de Creación de la Universidad Central. 
hacia el texto por crear, hacia el texto inexistente. Esto implica indagar "cómo desde la praxis y/o desde la teoría, una determinada estética, una visión del mundo, en un género literario, se moviliza para aportar una diferencia respecto a lo ya sabido" (Universidad Central, 2017, p. 37).

La investigación y las líneas de investigación que apoya los programas de formación en creación literaria, se enfocan en la investigación de la "praxis creadora" o, en otras palabras, en la investigación de la "creación literaria", que implica un proceso de investigación y de creación. Se concibe el ejercicio de creación literaria como posibilidad de indagación sobre la forma en que el lenguaje se hace literatura. Para escribir es necesario destruir el lenguaje y rehacerlo de otra forma, entrar en el mundo en el que lleva a cabo su obra de transformación y de negación (Blanchot, 2004). La "praxis creadora" se convierte entonces en una propuesta de la investigación, que tiene sus propias preocupaciones sobre el lenguaje, la literatura y la cultura.

Borgdorff $^{4}$ (2010, p. 9) distingue tres formas de investigación en las artes: investigación sobre las artes, investigación para las artes e investigación en las artes. Así, la investigación sobre las artes tiene como objeto de estudio la práctica artística para establecer conclusiones válidas sobre la práctica desde una distancia teórica; esto supone una separación entre el investigador y el objeto de investigación, lo que caracteriza este "tipo de investigación y del acercamiento teórico a las mismas son la "reflexión" y la “interpretación”. En la investigación para las artes, el propósito es instrumental en tanto que lo que se busca es conocer cuáles son los materiales, herramientas que "se necesitan para y durante el proceso creativo o para el producto artístico final” (p. 9). Finalmente, la investigación en las artes no acepta "la separación de sujeto y objeto, y no contempla ninguna distancia entre el investigador y la práctica artística, ya que ésta es, en sí, un componente esencial tanto del proceso de investigación como de los resultados de la investigación" (p. 10).

Basados en la categorización de Borgdorff, establecemos la caracterización de las formas de investigación en creación literaria: investigación sobre la creación e investigación en la creación literaria.

En creación literaria, la investigación sobre la creación y la investigación en creación literaria están en una relación de mutua implicación, ya que la investigación "se enfoca en los procesos de escritura, en cómo se escribe el texto, y no en el producto finalizado"s. Esta concepción se sustenta en una actitud activa, vigilante, que se pregunta por las "continuas transformaciones del arte literario, en función de la obra por crear". De manera que, la creación de una nueva obra se engendra en el conocimiento y rastreo de

los recursos de la creación literaria en cualquiera de sus géneros, a partir de obras y autores paradigmáticos de los diversos periodos de la tradición literaria universal, con el objetivo no solamente de desarmar y entender los "mecanismos de relojería de las obras y sus transformaciones respecto a obras anteriores, sino de concebir, a partir de este proceso, la nueva obra, la obra que se distancia de lo anterior, el llamado „texto inexistente".

\footnotetext{
$4 \quad$ Borgdorff distingue entre (a) investigación sobre las artes, (b) investigación para las artes y (c) investigación en las artes, con base en las diferencias establecidas por Christopher Frayling.

$5 \quad$ Estas ideas hacen parte del documento de investigación del Departamento de Creación Literaria 2018.
} 
Todo escritor necesita antepasados, asegura Elías Cannetti, para explicar cómo la fuerza y la vitalidad de los antepasados despierta al escritor o al lector. De este modo, el conocimiento de la herencia literaria, la tradición y las reflexiones sobre el arte, la literatura y la creación -desde el punto de vista de los escritores-, se imbrican en esta forma de investigación.

La creación literaria sitúa esta forma de investigación en un contexto actual, en una realidad que descubre la relación permanente entre el arte y el mundo social, en palabras de Jacques Rancière6, en tanto que sus universos están configurados como representaciones artísticas del mismo. En el proceso de creación, la relación entre poiesis (creación) y mimesis (imitación de la naturaleza), es el paso de la potencia (no-ser) a su concreción (ser) está mediado por la mimesis (lo real posible) y es su interacción la que hace surgir la diégesis (ficción) o discurso artístico. De ahí que, todo proceso artístico requiera del trabajo con lo que denominamos mundo de las cosas, pero también con el mundo de las obras. Dicho trabajo puede ser contemplado como tensión constante entre forma y sustancia, o la búsqueda de renovación, continuidad o ruptura con los discursos artísticos precedentes y de diálogo con el mundo social y cultural en el que se inscribe la obra.

De esta manera, la tensión entre el contexto actual y la producción de la obra, puede ser pensada desde dos perspectivas: el punto de vista de la formación de los creadores, la mirada de la investigación sobre el proceso de creación o la creación misma, justamente, porque toda obra construye mundos posibles (en su sincronía, a partir del diálogo con el mundo exterior de la obra, del lector, el público de su tiempo, $\mathrm{y}$, en su diacronía, en relación con la herencia literaria, el gran público, la recepción crítica o el canon).

\section{La construcción del campo de estudio}

Desde sus comienzos, el Departamento de Creación Literaria se propuso encontrar un camino que recoja toda la innovación y originalidad que suscita la creación literaria, sin menoscabo de la rigurosidad y profundidad reflexiva de la investigación literaria. Para que esto fuese posible, establecimos una estrecha relación entre investigación literaria y creación literaria; ambas como formas de producción de conocimiento; el primero, científico; el segundo, artístico. Siendo así, hasta el momento hemos podido concluir que en ambos casos se obtiene la generación de nuevo conocimiento, lo que varía de uno a otro no es necesariamente la ruta que se sigue, sino lo que se alcanza al finalizar dichos procesos. En el caso de la investigación artística, el producto es un texto literario (poesía, narrativa, ensayo, híbridos, performáticos); en el caso de la investigación literaria, un texto crítico, histórico o teórico.

trayectos que les permiten adherirse a una condición, reaccionan a situaciones, reconocen sus imágenes. Reconfiguran el mapa de lo sensible, mediante una difuminación de la funcionalidad de los gestos y los ritmos adaptados a los ciclos naturales de la producción, la reproducción y la sumisión” (p. 14).

6 Jacques Rancière en La división de lo sensible. En Estética y política (2002), el autor plantea al respecto que: "Volvemos a encontrar aquí la otra cuestión que se refiere a la relación entre literalidad e historicidad. Los enunciados políticos o literarios tienen efecto sobre lo real. Definen modos de palabra o de acción, pero también regímenes de intensidad sensible. Trazan planos de lo visible, trayectorias entre lo visible y lo decible, relaciones entre modos del ser, modos del hacer y modos del decir. Definen variaciones de las intensidades sensibles, de las percepciones y capacidades de los cuerpos. Se apoderan así de los seres humanos corrientes, ahondan distancias, abren derivaciones, modifican las maneras, las velocidades y los trayectos que les permiten adherirse a una condición, reaccionan a situaciones, reconocen sus imágenes. Reconfiguran el mapa de lo sensible, mediante una difuminación de la funcionalidad de los gestos y los ritmos adaptados a los ciclos naturales de la producción, la reproducción y la sumisión" (p. 14). 
Siguiendo este planteamiento, consideramos que dos son las rutas para la investigación en creación literaria: la primera de ellas, es la investigación sobre la creación; la segunda, es la investigación en creación o creación propiamente dicha. En el primer caso, estamos hablando de investigación literaria y pensamos que puede ser abordada de la manera como la convención del proceso lo indica. Para este camino, proponemos también dos vías: una es inductiva, parte de un estudio del arte, sigue el planteamiento de un proyecto, avanza en su desarrollo y culmina con un informe final en forma de artículo científico o ensayo crítico; la otra es deductiva, en la medida en que, basada en la experticia del investigador, se propone directamente la elaboración de un proyecto de investigación como punto de partida, que permita profundizar en el análisis del estado del arte como parte del propio desarrollo de la investigación y culmina de la misma manera que la primera vía, con un informe final en forma de artículo científico o ensayo crítico. Una síntesis del proceso sería el siguiente esquema:

\begin{tabular}{|c|c|}
\hline \multicolumn{2}{|c|}{ Figura 1. Investigación sobre la creación literaria } \\
\hline $\begin{array}{l}\text { Primera ruta: modelo in- } \\
\text { ductivo }\end{array}$ & Segunda ruta: modelo deductivo \\
\hline A. Indagación crítica & \multirow[t]{2}{*}{ Proyecto de investigación } \\
\hline $\begin{array}{l}\text { B. Proyecto de investiga- } \\
\text { ción }\end{array}$ & \\
\hline $\begin{array}{l}\text { Informe final: ensayo crí- } \\
\text { tico, artículo científico }\end{array}$ & $\begin{array}{l}\text { Informe final: ensayo crítico, artículo cien- } \\
\text { tífico }\end{array}$ \\
\hline
\end{tabular}

Desde la segunda ruta, investigación artística, el proceso puede ser abordado por dos vías. Por una, desde el modelo inductivo, se parte de la indagación crítica, se desarrolla un proyecto de creación y se culmina con el texto literario. Por la otra, basada en la experticia del creador, se puede proponer la elaboración de un proyecto de creación que continúa con la escritura del texto literario, al mismo tiempo que se hace la reflexión sobre la forma deconstruirlo. Consideramos que, en este caso, se sigue el modelo abductivo, en la medida en que la oscilación del todo a las partes y de las partes al todo es la manera como puede explicarse la constante indagación que implica este modo de creación literaria: por un lado, la escritura misma del texto literario; por el otro, la reflexión sobre la forma de construirlo. Ese ir y venir entre la reflexión y la acción podemos equipararlo al juego abductivo de construir y reconstruir hipótesis a lo largo de la investigación. El siguiente esquema resume lo propuesto:

\begin{tabular}{|l|c|}
\hline \multicolumn{2}{|c|}{ Figura 2. Investigación desde la creación literaria } \\
\hline \multicolumn{1}{|c|}{ Primera ruta inductiva } & Segunda ruta abductiva \\
\hline A. Indagación crítica & \multirow{2}{*}{ Proyecto de creación } \\
\cline { 1 - 1 } B. Propuesta de creación & \\
\hline Texto literario & $\begin{array}{c}\text { Texto literario } \\
\text { Diario de escritura }\end{array}$ \\
\hline
\end{tabular}

Ahora bien, en nuestros programas académicos hemos optado por fortalecer la segunda vía, la de investigación en creación, entendida como nuestra manera de aplicar la Formación en investigación, ya que 
la opción de grado (tanto para el Pregrado como la Maestría en Creación literaria) que tenemos hasta el momento, es la de la producción de un texto artístico (ensayo, novela, poesía, híbrido o performático). Sin embargo, en el procedimiento seguimos el modelo inductivo, parten de la indagación crítica, elaboran el proyecto y culminan con la obra literaria.

En el caso del Pregrado, a lo largo de la carrera tienen una línea de profundización "crear", a la que se le denomina "proyecto integrado". Desde esta línea, en el ciclo básico se parte del conocimiento y dominio del lenguaje, de las formas literarias y su uso estético; en el ciclo de formación para la creación, experimentan con las formas de composición, poética, ensayística y narrativa, para desembocar en el proyecto de creación que dialoga con el Seminario de profundización. El proyecto integrado culmina con la obra literaria como opción de grado. Un esquema de lo aquí planteado, sería:

\begin{tabular}{|l|l|l|l|l|l|}
\hline & \multicolumn{3}{|l|}{ Figura 3. Ciclo de formación básica } & & \\
\cline { 2 - 6 } & & $\begin{array}{l}\text { Orígenes y desarrollo } \\
\text { del español }\end{array}$ & & & \\
\hline
\end{tabular}

\begin{tabular}{|c|c|c|c|c|c|c|}
\hline \multirow{3}{*}{ 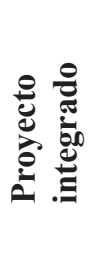 } & & \multicolumn{5}{|c|}{ Figura 4. Ciclo de formación para la creación } \\
\hline & Conocer & & & & $\begin{array}{l}\text { Seminario de } \\
\text { Profundización }\end{array}$ & \\
\hline & Crear & $\begin{array}{l}\text { Composición } \\
\text { narrativa }\end{array}$ & $\begin{array}{l}\text { Composición } \\
\text { poética }\end{array}$ & $\begin{array}{l}\text { Composición } \\
\text { ensayística }\end{array}$ & $\begin{array}{l}\text { Proyecto de } \\
\text { creación }\end{array}$ & (opción de grado) \\
\hline
\end{tabular}

Para el caso de la Maestría, el proceso de formación en creación literaria también se asume desde el modelo inductivo, partimos de la indagación crítica y culminamos con la obra literaria. La idea es hacer un acompañamiento integrado desde la búsqueda inicial hasta el texto literario. Para ello, se comienza con las exploraciones iniciales que permitan la delimitación de una propuesta de creación; posteriormente, se concreta en un proyecto de creación que se desarrolla en tres momentos: Proceso de creación (primeros adelantos de la obra), Obra I (primer borrador de la obra), Obra II (reescritura y reflexión final). Un esquema de la propuesta sería el siguiente:

\begin{tabular}{|l|c|c|c|c|}
\hline \multicolumn{2}{|l|}{ Figura 5. Línea de creación: proyecto integrado } \\
\hline Propuesta literaria & $\begin{array}{c}\text { Proyecto de } \\
\text { creación }\end{array}$ & $\begin{array}{c}\text { Proceso de } \\
\text { creación }\end{array}$ & Obra I & Obra II \\
\hline
\end{tabular}


Como cierre, nos gustaría plantear la dificultad que representa para los Programas de creación literaria (escrituras creativas), la consideración de la tensión entre investigación y creación en el contexto actual. En la medida en que no se reconoce el lugar de la creación dentro del campo de los estudios literarios, ni tampoco en el de las artes. Nos hemos planteado como reto el fortalecimiento de la creación literaria como otra forma dentro de los estudios literarios (hasta ahora centrados en la historia, teoría, crítica y pedagogía de la literatura), sobre la base de que nuestro campo de acción genera conocimiento sobre la literatura desde otros ámbitos.

Consideramos que el aporte de los nuevos programas al campo de los Estudios Literarios, enriquece el objeto de estudio, en lugar de restarle validez académica. Nuestra apuesta es por la consolidación de la creación como investigación artística. Esto supone una intervención social, puesto que crea y desarrolla un nicho de estudios que no existía en el país.

Un ejemplo del vacío de la creación en el campo literario es la creación literaria. En los Estudios literarios, se consideran tres disciplinas básicas: la historia, la teoría y la crítica. La pedagogía de la literatura no se considera una disciplina, una situación similar atraviesa a la creación literaria.

El problema se agrava cuando tampoco se le vincula con las otras artes. Tal vez por una falsa idea anquilosada en el campo, según la cual la creación literaria es un proceso cien por ciento "intuitivo". Entonces, la creación literaria es invisible en la plataforma Scienti de Colciencias, que registra a los investigadores y los grupos de investigación del país. Si revisamos el campo en el que se debería registrar nuestras actividades, la opción evidente sería "Humanidades":

Figura 6. Registro de Información

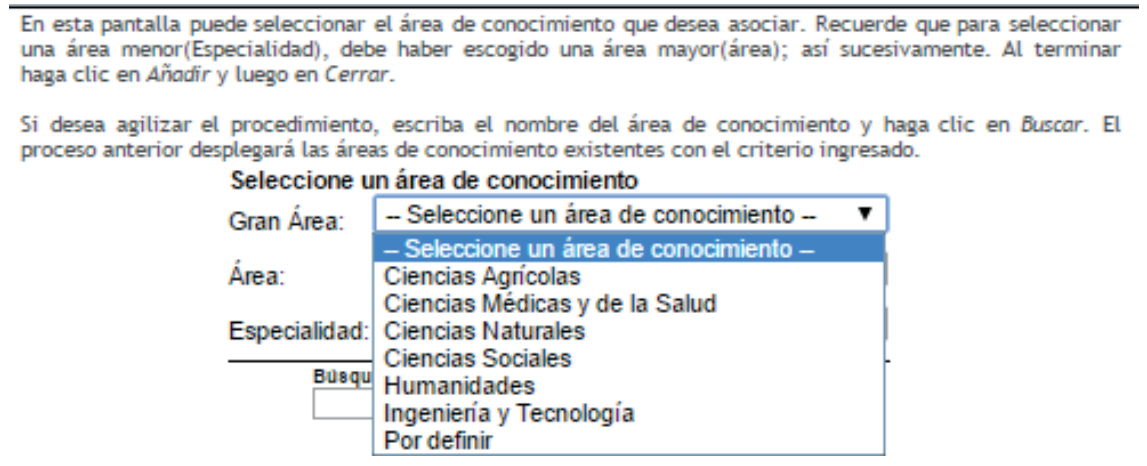

Fuente : https://scienti.colciencias.gov.co/publindex/EnRevista/ingresar.do

Hasta aquí, en esta "Gran Área”, todo bien; el problema empieza a darse en el espacio del "Área”, ¿en dónde ubicarnos?, ¿ “Arte” o "Idiomas y Literatura"? Ni siquiera existe un espacio para los Estudios Literarios, indisolublemente ligados a los idiomas. Y no hay nada despectivo en esta apreciación, es solo la constancia de que se asimila a la literatura como instrumento de la enseñanza. Pero eso es otra cuestión. Digamos que se nos presenta la paradoja de elección: 
Figura 7. Registro de Información

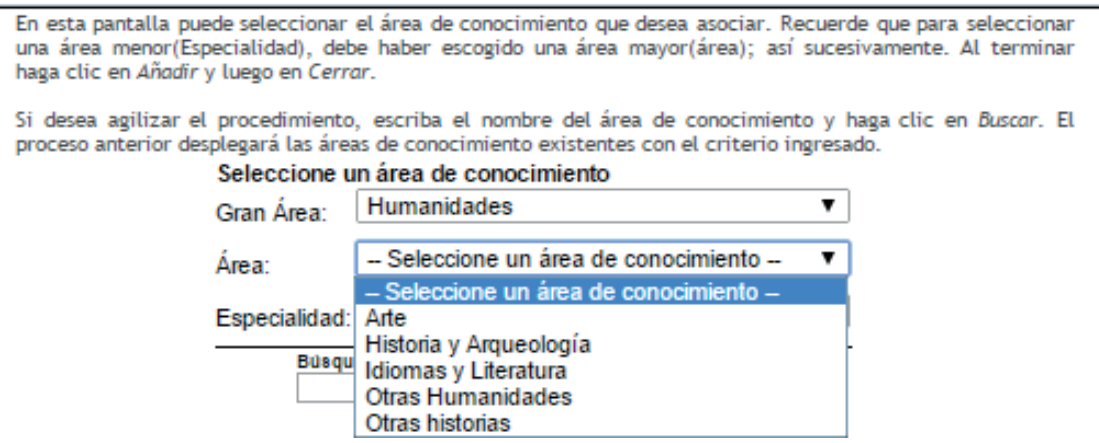

Fuente : https://scienti.colciencias.gov.co/publindex/EnRevista/ingresar.do

Supongamos que elegimos la opción del campo de las artes. Al intentar seleccionar un área de conocimiento dentro de la „Especialidad ${ }^{\text {ee }}$, nos damos cuenta de que no está la Creación Literaria o Escrituras Creativas. ¿Todavía se parte del prejuicio de que la escritura de textos literarios, la creación literaria, no es un arte y por lo tanto no aparece tampoco en esta área?, según Colciencias, como se evidencia en el siguiente cuadro, parece que no.

Figura 8. Registro de Información

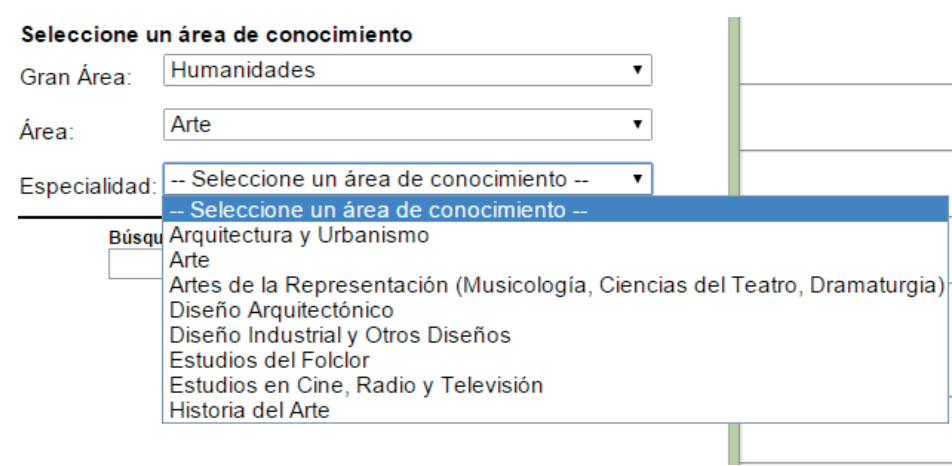

Fuente : https://scienti.colciencias.gov.co/publindex/EnRevista/ingresar.do

Diríamos que nos queda la opción de „Idiomas y Literatura“. Afortunadamente, se puede agregar en "Estudios Literarios" dentro de las especialidades de esta Área. Lo hacemos así, porque consideramos que es necesario que se acepte a la creación literaria al lado de la teoría, la crítica y la historia literaria. Solemos inscribir la producción en y sobre Creación Literaria. El inconveniente grave es que aún no se le acepta en este campo como una de sus formas. Esa es una de las problemáticas centrales de la creación literaria, se le excluye del campo de los Estudios literarios, pero también de las Artes. Entonces, ¿qué es la creación literaria?, ¿cuál es su lugar dentro de los estudios literarios? ¿No es un arte?. A este lugar incómodo de la creación literaria, hay que sumarle la camisa de fuerza que significa la clasificación de 
los productos de la investigación artística. Muchas investigaciones en el campo culminan con la publicación de un libro de cuentos, una novela o un libro de ensayo, no puede ser ubicado como libro producto de investigación, según la reglamentación de COLCIENCIAS, como lo ilustra el verificador:

\section{Figura 9. Requisitos para el registro de libros de investigación publicados en Colombia}

Definición de Colciencias de libro resultado de investigación, Una publicación
original e inédita, cuyo contenido es el resultado de un proceso de investigación;
que -previo a su publicación- ha sido evaluado por parte de dos pares académicos;
que ha sido seleccionada por sus cualidades científicas como una obra que hace
aportes significativos al conocimiento en su área y da cuenta de una investigación
completamente desarrollada y concluida. Además, esta publicación ha pasado por
procedimientos editoriales que garantizan su normalización bibliográfica y su
disponibilidad.
OJo, En esta definición de libro resultado de investigación no están contemplados
las siguientes publicaciones, aun en el caso de que hayan pasado por un proceso
de evaluación por pares académicos, resúmenes, estados del arte; presentación de
hallazgos de investigaciones no concluidas; libros de texto; libros de apoyo
pedagógico; libros de enseñanza de idiomas; entrevistas; manuales; cartillas;
ensayos; memorias de eventos; libros de poesia y novelas; ni traducciones.

Fuente : http://bibliotecadigital.magisterio.co/blog/requisitos-para-el-registro-de-libros-de-investigaci-n-publicados-en-colombia

De ahí que sea tan preocupante el vacío en el que queda la creación literaria dentro de la investigación. Necesitamos generar un espacio dentro de los Estudios Literarios para las investigaciones que se hacen sobre la creación literaria, los procesos, las obras, los recursos desde el punto de vista del escritor para la producción específica en nuestro campo, como debería ser y como se proyecta como ideal en la siguiente imagen:

\section{Figura 9. Registro de Información}

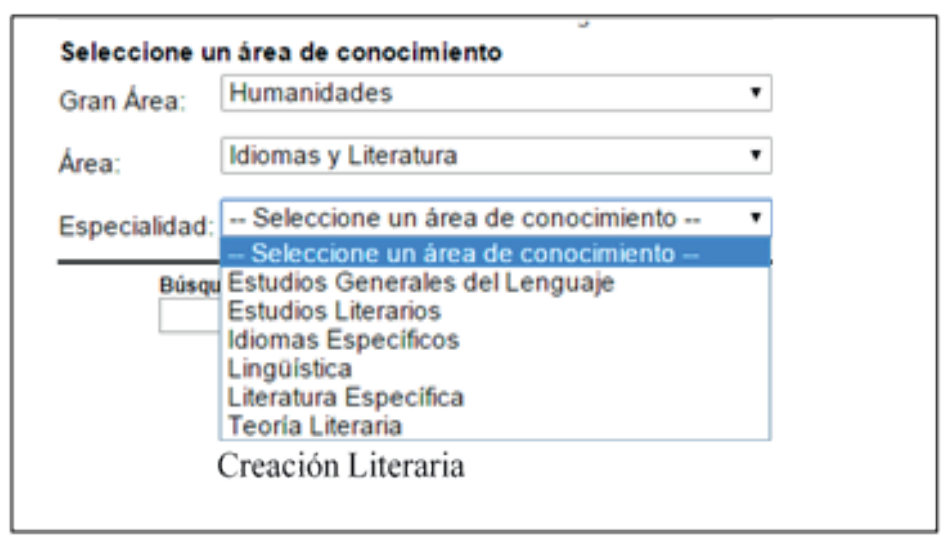

Fuente : https://scienti.colciencias.gov.co/publindex/EnRevista/ingresar.do 
Pero, también debería haber un lugar en el campo del Arte, pues el mismo problema de desconocimiento ocurre en el caso de la producción artística de la creación literaria. Cuando se intenta agregar un producto artístico, como novela, libro de cuentos, libro de poesía, de ensayo o cualquiera de los géneros literarios, no es posible hacerlo, porque las categorías que se proponen no se ajustan a los formatos de la creación literaria (que suelen ser textos escritos y no eventos):

Figura 10. Registro de Información

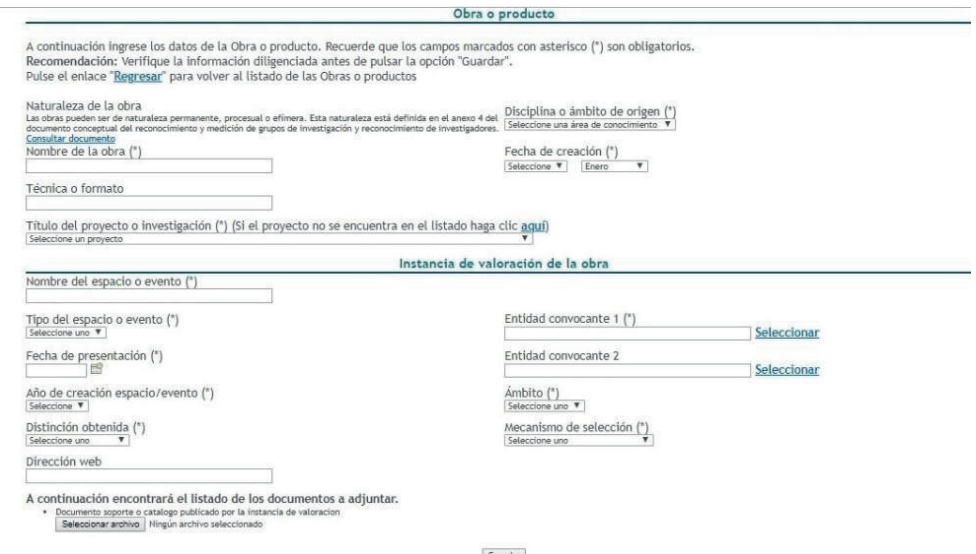

Fuente : https://scienti.colciencias.gov.co/publindex/EnRevista/ingresar.do

Como puede verse en la ilustración, las categorías corresponden más al tipo de obra efímera (musical, dramatúrgica, etcétera), cuyo registro es difícil de validar, si no es a través de elementos como "Técnica o formato", "Nombre del espacio del evento". No estamos negando la importancia de este espacio de registro de la "Producción en artes, arquitectura y diseño", pero también es preciso pensar el lugar de la creación literaria en campo de las artes y la necesidad de generar categorías propias de esta especialidad. Así como es urgente abrir un espacio para la Creación Literaria dentro de las especialidades del Arte:

\section{Figura 11. Registro de Información}

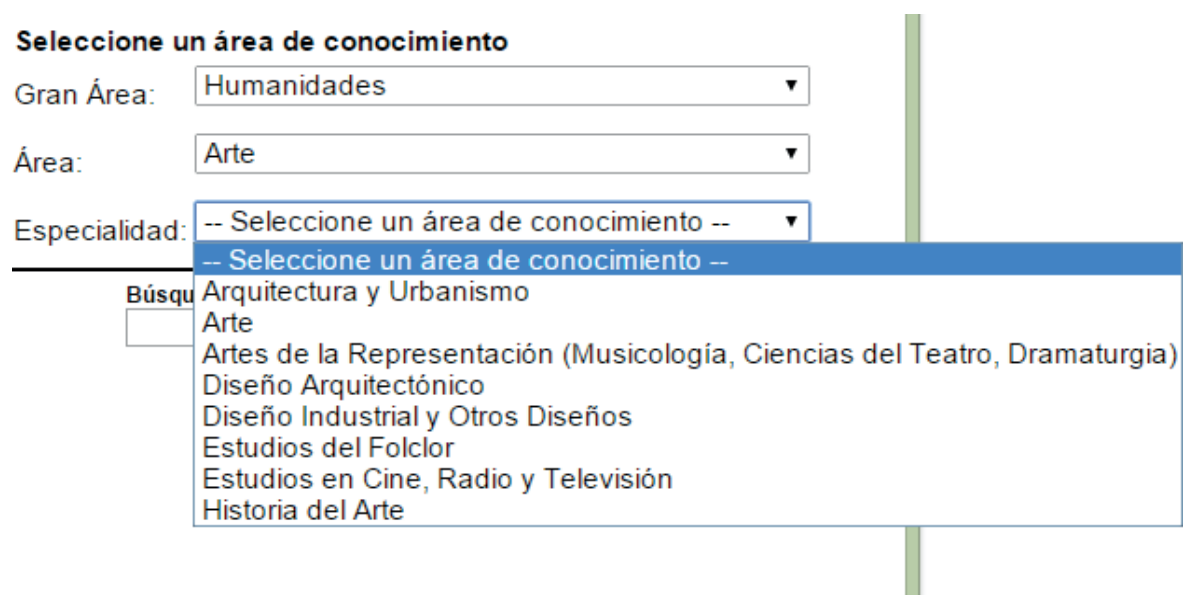


Fuente : https://scienti.colciencias.gov.co/publindex/EnRevista/ingresar.do

Para que esto sea posible, desde nuestra concepción es necesario que se valide a la creación como una de las formas posibles de investigación; es decir, como un „,campo de estudio ${ }^{\text {ee }}$, cuyo objeto es el proceso de escritura de textos literarios y que, desde la tradición literaria europea, se le ha denominado „creación literaria ${ }^{e e}$. Es tiempo de aceptar que existe una relación dinámica entre creación e investigación que enriquece las investigaciones en general y a la creación literaria en particular, y que preferimos nombrar investigación artística.

\section{Referencias}

Borgdorff, H. (2010). El debate sobre la investigación en las artes. Cairon, Revista de Ciencias de la Danza, (13), 25-46.

López Cano, R., y San Cristóbal, Ú. (2014). Investigación artística en música. Problemas, métodos, experiencias y modelos. Conalculta: Barcelona. Oído pensante, 4(2), 1-8.

López Cano, R. (2015). Educar para la investigación-creación: áreas de trabajo, tipos de conocimiento y problemas de implementación. A contratiempo. Revista de música en la cultura, 25. Recuperado el 29 febrero de 2019, de Universidad central http://www.musigrafia.org/ acontratiempo/?ediciones/revista-25/artculos/educar-para-la- investigacin-creacin-reas-detrabajo-tipos-de-conocimiento-y-problemas-de-implementac.html.

Maillard, C. (2014). El misterioso soporte de la impresiones. En G. Schwartz y V. Bermúdez (ed ña: Next Door Publishers. 